\title{
KONSEP IJTIHAD PROGRESIF ABDULLAH SAED DALAM MENGATASI PROBLEMATIKA KONTEMPORER
}

\author{
Afifullah \\ Sekolah Tinggi Agama Islam Negeri (STAIN) Pemekasan
}

\begin{abstract}
In the history of Islamic civilization, Islam once ruled the world with the rapid development of science and both naqli aqli discovered and developed by Muslim scholars. The development of science reaches its zenith at the time of Abbasiyah dynasty centered in Baghdad (Iraq). The success achieved by Muslim scholars at the time it was not a coincidence, but derived from hard work and sincerity of Muslim scholars at the time. However, with the passing of time the development of science in the Muslim world was decline, compared with Europe rapidly developing science (renaissance). Along with the decline of science in the Muslim world today makes Abdullah Saeed think hard to provide a solution to this problem, so he offered a progressive Islamic ideas with progressive methods ijtihadis, so that science in the Islamic world back to the point of its greatness.
\end{abstract}

Keywords: Progressive Muslims, Islam Progressive and Progressive Ijtihadis

\section{PENDAHULUAN}

Istilah pemikiran Islam dalam literatur barat sering disebut dengan istilah Islamic Thought atau dalam literatur bahasa Arab disebut al-Fikr al-Islamy.Istilah ini sepenuhnya bukan istilah yang 
terdapat dalam al-Qur'an maupun hadith.Tetapi istilah pemikiran Islam merupakan istilah yang lahir dari gerakan pemikiran yang diwujudkan oleh tokoh Islam.Dalam buku yang ditulis oleh Arkun, memunculkan istilah tersebut atas dasar perhatian Arkun terhadap fakta kondisi Islam pada masanya.Ia melontarkan kritik terhadap kondisi umat Islam yang jauh dari keterbelakangan dibandingkan dengan orang-orang barat. Selain itu, ia juga menawarkan solusi atas keterpurukan kondisi umat Islam. ${ }^{1}$

Tulisan ini ingin mendalami pola pemikiran Islam Progresif dan Ijitihad Progresif yang ditawarkan oleh Abdullah Saeed, yang didekasikan untuk memberikan solusi terhadap keterbelangan yang berkaitan dengan ketidakmampuan "cara berfikir" dan "analisis keilmuan" yang dikembangkan ilmu-ilmu agama (Ulum al-Din) dalam menjawab problem-problem modernitas dan kebutuhan kontemporer. Hal ini disebabkan beberapa alasan; pertama, pola pemikiran "ijtihad progresif" yang dikembangkan oleh Abdullah Saeed sebagai jawaban atas studi/penelitian atau pemetaan yang dilakukannya sendiri atas trend pemikiran muslim kontemporer dan dianggap paling tepat untuk menjawab problem modernitas dan kebutuhan kontemporer. kedua, Abdullah Saeed, sebagai penggagasnya adalah muslim yang lahir, besar dan bekerja di Australia. Dimana Australia penduduknya mayoritas non Muslim, disamping itu juga Australia merupakan negara dengan sistem pemerintahan yang dibangun atas dasar demokrasi liberal. Walaupun Abdullah Saeed hidup di negara tersebut, akan tetapi ia sangat menguasai khazanah intelektual Islam dan mempunyai basis pendidikan Islam di Timur Tengah. Ketiga, disamping itu, pola pemikirannya dipandang lebih maju karena berupaya mendialogkan

${ }^{1}$ Muhammad Arkun, al-Fikr al-Islamy: Naqdu wa Ijtihad, (Bairut: alMuassisah al-Wathaniyah li al-Kitab, 1989), 3. 
antara "cara berfikir" dan "analisis keilmuan" yang dikembangkan ilmu-ilmu agama seperti tafsir, hadith, kalam, fiqh, dan tasawuf dengan cara berfikir dan analisis keilmuan dalam ilmu-ilmu sosial seperti sejarah, filsafah, sosiologi, antropologi, dan hukum. Keempat, sekaligus secara pragmatis, menghadirkan tulisan/ijtihad Abdullah Saeed dari Australia dimaksudkan untuk memberikan penyadaran dan pembelajaran bagi Muslim yang tinggal di negaranegara yang mayoritas Muslim, bahwa ada genrebaru kelompok masyarakat dan corak intelektual Muslim yang tumbuh berkembang di wilayah benua-benua yang berpenduduk mayoritas non Muslim, seperti Australia dan sebagainya.

\section{PEMBAHASAN}

\section{Sekilas Biografi Abdullah Saeed ${ }^{2}$}

Abdullah Saeed adalah seorang the Sultan of Oman Professor of Arab and Islamic Studies.Dia sekarang bekerja sebagai Director of the Center for the Study of Contemporary Islam pada Universitas Melbourne, Australia.Dia mengenyam pendidikan di dunia Arab dan Barat. Berikut latar pendidikannya:

a. Arabic Language Study, Institute of Arabic Languange, Islamic University, Madinah, Saudi Arabia

b. High School Certificate, Secondary Institut, Madinah, Saudi Arabia

c. Bachelor of Arts, Arabic and Islamic Studies, Islamic University, Madinah, Saudi Arabia

${ }^{2}$ Lebih jelasnya baca pada www.abdullahsaeed.org. 
184 Rausyan Fikr, Vol. 12 No.2 Desember 2016: 181 - 210

d. Master of Arts Preliminary, Middle Eastern Studies, University of Melbourne, Australia

e. Master of Arts, Applied Linguistics, University of Melbourne

f. Doctor of Philosophy, Islamic Studies, University of Melbourne, Australia.

Setelah menyelesaikan program doctoral-nya, dia diangkat menjadi dosen pada Department of Asian Languages and Anthropology, Universitas Melbourne. Kemudian pada tahun 2000, dia memperoleh status sebagai Associate Professor di institusi yang sama. Tiga tahun kemudian dia mendapat status Full Professor dan diangkat menjadi the Sultan of Oman Professor of Arab and Islamic Studies. Meskipun sudah diangkat menjadi Professor di the Sultan of Oman, dia tetap menjalankan aktifitasnya sebagai Director of the Center for the Study of Contemporary Islam pada Universitas Melbourne.

Abdullah Saeed dikenal sebagai scholar yang cukup produktif.Dia menulis beberapa artikel dan buku.Berikut adalah tulisan-tulisan yang pernah dipublikasikan selama karirnya.Tulisan yang berbentuk artikel sebagaimana daftar berikut ini.

a. "Trends in Contemporary Islam: A Preliminary Attempt at a Classification” Journal of the Muslim World. Volume 91, 2007.

b. "Nurcholish Madjid and Contextualised Understanding of the Qur'an", Suha TajiFarouki (ed.). Modern Muslim Intellectuals and the Qur'an. Oxford: University Press in association with The Institute of Ismaili Studies, 2006. 
c. "Creating a Culture of Human Rights from a Muslim Perspective", Cultivating Wisdom, Harvesting Peace: Educating for a Culture of Peace through Values, Virtues, and Spirituality of Diverse Cultures, Faiths, and Civilizations, Multi-Fai, 2006.

d. "Qur'an: Tradition of Scholarship and Interpretation", Encyclopedia of Religion. Farmington MI: Thomson Gale USA. 10 pp., 2005.

e. "Muslims", Encyclopedia of Melbourne. Melbourne: Oxford University Press. 1p. 2005.

f. "Islamic Religious Education and the Debate on its Reform Post-September 11", S. Akbarzadeh and S. Yasmeen (eds.), Islam and the West: Reflections from Australia. Sydney: UNSW Press. 14pp. 2005.

g. "Islamic Banking and Finance: In Search of a Pragmatic Model', Virginia Hooker and Amin Saikal (eds), Islamic Perpsectives on the New Millenium. Singapore: Institute of Southeast Asian Studies, 2004.

h. "Sarraf", Encyclopedia of Islam. Leiden: EJ Brill, 2004.

i. "The Need to Rethink Apostasy Laws", Freedom of Religion, Apostasy and Islam, chapter 13, pages pp. 167-173. Ashgate Publishing Limited, 2004.

j. "Islam and Politics", S Akbarzadeh \& A Saeed (eds.) Islam and Politcal Legitimacy. London: RoutledgeCurzon, 2003.

k. "The Official Ulema and Religious Legitimacy of the Modern Nation State", S Akbarzadeh \& A Saeed (eds.) Islam and Politcal Legitimacy. London: RoutledgeCurzon, 2003. 
1. "Coinage" Richard C Martin (ed.), Encyclopedia of Islam and the Muslim World. New York: Macmillan Reference USA, 2003.

m. "Ummah", Richard C Martin (ed.), Encyclopedia of Islam and the Muslim World. New York: Macmillan Reference USA, 2003.

n. "The Muslim Communities in Australia: the Building of a Community", Yvonne Yazbeck Achmad Zaini 30 ISLAMICA, Vol. 6, No. 1, September 2011 Charles J. Adams Antara Reduksionisme dan Anti-Reduksionisme dalam Kajian Agama Haddad and Jane I. Smith (eds.). Muslim Minorities in the West: Visible and Invisible. California: Altamira Press, 2002.

o. "Economics", Jane Dammen McAuliffe (ed.). Encyclopaedia of the Qur'an. Vol. 2, Leiden: EJ Brill, 2002.

p. "Jihad and Violence: Changing Understandings of Jihad among Muslims", Tony Coady and Michael O'Keefe (eds.). Terrorism and Justice: Moral Argument in a Threatened World. Melbourne: Melbourne University Press, 2002.

q. "The Charge of Distortion of Jewish and Christian Scriptures", The Muslim World. Vol. 92, 2002.

r. "Searching for Identity: Muslims in Australia Abdullah Saeed and Shahram Akbarzadeh (eds.). Muslim Communities in Australia. Sydney: UNSW Press, 2001.

s. "Muslim Community Cooperative of Australia as an Islamic Financial Service Provider", Abdullah Saeed and Shahram Akbarzadeh (eds.). Muslim Communities in Australia. Sydney: UNSW Press, 2001. 
Sedangkan tulisan Abdullah Saeed yang sudah dipublikasikan dalam bentuk buku sebagaimana daftar berikut ini.

a. The Qur'an: An Introduction, Routledge, 2008.

b. Islamic Thought an Introduction, Routledge, 2006.

c. Approaches to the Qur'an in Contemporary Indonesia, Oxford University Press in association with The Institute of Ismaili Studies, 2006.

d. Interpreting the Qur'an: Towards a Contemporary Approach, Routledge, 2005.

e. Muslim Australians: Their Beliefs, Practices and Institutions, Commonwealth Government, 2004. Islam in Australia, Allen and Unwin, 2003.

f. Islam and Political Legitimacy, Routledge/Curzon Press, 2003.

g. Muslim Communities in Australia, UNSW Press, 2001.

h. Islamic Banking and Interest: A Study of the Prohibition of Riba and its Contemporary Interpretation, EJ Brill, 2001.

i. Essential Dictionary of Islamic Thought, Seaview Press, 2001.

j. Introduction to Modern Standard Arabic, Melbourne: MIALS 2001.

k. Modern Standard Arabic, Book 1, Melbourne: MIALS 2001. 
1. Modern Standard Arabic, Book 2, Melbourne: MIALS 2001.

m. Modern Standard Arabic, Book 3, Melbourne: MIALS 2001.

n. Modern Standard Arabic, Book 4, Melbourne: MIALS 2001.

\section{Trend Pemikiran Muslim Kontemporer dan Pengembangan Islam Progresif Abdullah Saeed}

Abdullah Saeed mencoba melakukan studi pemetaan terhadap trend pemikiran umat Islam kontemporer dan menemukan 5 kelompok pemikiran Islam.ia mengelaborasi ke enam trend pemikiran Islam kontemporer tersebut secara luas dalam bukunya "Islamic Thought: An Introduction" sebagai berikut:

a. Legalis Tradisionalis

Legalis Tradisionalis adalah sekelompok komunitas yang mengikuti pola fiqh pada madzhab hukum Islam dan teologi pramodern.Mereka berusaha merelevansikan produk yang dihasilkan oleh pakar hukum Islam pra-modern.Mereka terpanggil untuk melakukan kritik dan pembaharuan terhadap hukum Islam pramodern.Hal ini banyak dilakukan oleh beberapa lembaga pendidikan di berbagai negara, seperti Timur Tengah, Afrika, dan lain sebagainya.

Taklid buta menjadi sebuah ciri khas dari kaum Islam pada abad kelima/kesebelas hingga pada masa modern. Secara historis, berbagai negara telah memutuskan untuk mengikuti salah satu madzhab hukum Islam, sebut saja Arab Saudi, mereka memutuskan untuk bermadzhab Hambali, Malaysia dan Indonesia bermadzhab 
Syafi'i. Para pakar Islam selalu berkampanye untuk menyuarakan pentingnya hukum Islam.Oleh karena itulah, dominasi interpretasi atas hukum Islam masih cukup kuat di masyarakat sebagai perwakilan kelompok ortodok.

Dalam hal ini Abdullah Saeed menjadikan Yusuf Qardhawi sebagai contoh dalam golongan ini.Qardhawi sangat populer di beberapa negara di dunia.Ia dikenal sebagai ulama yang berani dan kritis. Pandangannya sangat luas dan tajam.Karena itu, banyak pihak yang merasa "gerah" dengan berbagai pemikirannya yang seringkali dianggap menyudutkan pihak tertentu, termasuk Pemerintah Mesir.Akibat pandangan-pandangannya itu pula, dia harus mendekam dibalik jeruji besi. Namun, demikian ia tidak pernah berhenti menyuarakan dan menyampaikan pandanganpandangannya, dalam membuka cakrawala umat.

Ia telah banyak menerbitkan buku hasil dari pergulatan intelektualnya, kurang lebih empat puluh buku yang sudah ditulisnya. Buku-buku yang ditulisnya seputar aspek-aspek kehidupan sosial.Salah satu tulisan dalam bukunya yaitu fokus terhadap syari'ah tradisional dengan mengaktualkan dengan pemahaman-pemahaman masalah kontemporer.Dengan demikian, secara faktual tulisannya banyak diterima di berbagai kalangan umat Islam.

Dalam satu kasus yang menghebohkan dunia pemikiran hukum Islam terhadap pernyataan dari Amina Wadud terkait keabsahan seorang perempuan menjadi imam atas laki-laki dalam sholat.Dalam kontek ini, tampak jelas Qardhawi menunjukkan sikap sebagai tokoh hukum Islam tradisionalis.Ia bersikukuh melarang seorang perempuan menjadi imam atas laki-laki dalam sholat. Sebagaimana dalam stetemennya ia mengatakan: 
Sepanjang sejarah Islam tidak pernah seorang wanita memimpin sholat untuk laki-laki.Bahkan selama pemerintahan Shajarat al-Durr (w. 659/1259) tidak pernah ditemukan hal demikian.

Qardhawi menyatakan bahwa yang boleh menjadi imam sholat hanya laki-laki atas laki-laki.Sholat merupakan sebuah ritual dengan beberapa gerakan yang tidak memungkinkan wanita menjadi imam karena secara natural kondisi fisik perempuan dapat membangkitkan hawa nafsu laki-laki sehingga akan mengganggu perhatian dan konsentrasi mereka, serta menghilangkan atmosfer spritual yang dibutuhkan dalam sholat.

Padangan Qardhawi di atas mewakili pendapat mainstream pemikir Islam terkait kepemimpianan perempuan dalam ibadah. Dasar penolakannya terhadap imam perempuan tersebut dengan alasan bahwa perempuan adalah "pembangkit birahi kaum pria."Hal itu menyiratkan pemikirannya bahwa eksistensi perempuan dikonsepsikan hanya sebagai makhluk sensual, dimana tubuhnya hanya dimaknai sebagai lokus perangsang nafsu laki-laki. ${ }^{3}$ Konsepsi ini kemudian dijadikan legitimasi untuk membatasi gerak perempuan pada ruang-ruang domestik karena kebebasan untuk mengakses dunia publik justru akan menimbulkan fitnah. Wacana keagamaan di atas, secara lebih luas akan berpengaruh terhadap bangunan pemikiran Islam terkait persoalan-persoalan yang berhubungan dengan perempuan. Konstruksi agama yang mendefinisikan perempuan sebagai makhluk sensual juga akan berimplikasi terhadap pandangan perempuan sendiri, terhadap eksistensi, dan makna tubuhnya. Oleh karena itu, kajian terhadap kepemimpinan perempuan dalam shalat sangat signifikan karena

${ }^{3}$ Abdullah Saeed, Islamic Thought and Introduction, (New York: Routledge, 2006), 143. 
seperti halnya nilai-nilai, gagasan-gagasan, dan ideologi-ideologi sebagai suprastruktur akan berpengaruh kepada struktur masyarakatnya. Dengan demikian, maka gagasan dan nilai-nilai agama akan memiliki pengaruh besar terhadap pemikiran dan praktik sosial penganutnya. Di samping itu, persoalan ini juga memberikan dampak sosial yang lebih luas ketika bersentuhan dengan sistem dan budaya kapitalisme.

Dengan Abdullah Saeed menjadikan Qardhawi sebagai contoh dalam kelompok ini dan mengutip pendapatnya Qardhawi berkaitan dengan boleh tidaknya perempuan menjadi imam atas laki-laki. Menurut penulis Abdullah Saeed ingin menunjukkan bahwa dalam hukum Islam ada beberapa hukum Islam ada yang perlu di Maqasid al-Syariah sesuai dengan permasalahan kontemporer, di sisi lain ada juga hukum Islam yang sumber referensinya bersumber dari ulama fiqh klasik.

b. Political Islamists

Pemikiran politik Islam kontemporer mulai muncul di akhir abad ke-XIX, hal ini dilatarbelakangi oleh keadaan dunia Islam yang berada dalam kemunduran disebabkan faktor internal dan ekternal, dari sudut faktor internal sebagai berikut; masalah kepemimpinan sosial, ekonomi, dan keagamaan yang mengakibatkan lahirnya gerakan-gerakan pemurnian dan pembaharuan. Di samping itu faktor eksternal adalah banyaknya negara-negara Islam yang berada di bawah penetrasi barat, maka secara otomatis terpecahlah keutuhan politik Islam yang pernah mengalami kejayaan di masa lalu.Sikap penjajah yang mengadakan intervensi bidang ekonomi dan militer di daerah jajahannya itu menyebabkan timbulnya sikap anti Barat dikalangan umat Islam, India, dan negara-negara lainnya. Di sisi lain pihak Barat harus diakui sebagai negara yang mempunyai 
keunggulan di bidang ilmu pengetahuan dan teknologi melebihi negara-negara Islam, meski pada awalnya ilmu tersebut juga berasal dari orang Muslim, maka dari itu untuk mencapai kemajuan dan melepaskan diri dari kondisi yang suram yakni kebodohan dan ketertinggalan itu, umat Islam harus belajar dari Barat.

Dilatarbelakangi keadaan seperti di atas, maka lahirlah pemikir-pemikir Islam yang mencoba mencari solusi dengan mencoba mengungkapkan ide-ide pembaharuan, termasuk pembaharuan di bidang politik yang mengaitkan antara Islam dan negara.Tetapi hal ini menjadi topik diskusi yang sangat menarik. Bila diperhatikan gagasan-gagasan politik yang dikemukakan oleh pakar-pakar tersebut, sebagaimana yang diungkapkan oleh Munawir Sjadzali; Para pakar (pakar Islam) mempunyai pola fikir yang berbeda dalam mengaitkan Islam dan negara, sehingga bisa dikelompokkan kepada tiga aliran yaitu: ${ }^{4}$

1. Mereka yang berpendirian bahwa Islam itu adalah Agama yang Sempurna dan Peripurna, sehingga dapat mengatur segala aspek kehidupan masyarakat termasuk kehidupan bernegara. Tokoh yang berpendapat seperti ini adalah Hasan al-Banna, Rashid Ridha, Sayyid Quthub, Abu A'la alMaududi.

2. Mereka yang berpendapat bahwa Islam itu tidak ada kaitannya dengan urusan kenegaraan seperti Ali Abd-Raziq dan Thaha Husein.

3. Orang yang berpendapat bahwa Islam itu adalah agama yang lengkap dengan perangkat tata-nilai kehidupan bernegara tetapi memuat bagaimana sistem ketatanegaraan yang baik

${ }^{4}$ Munawir Sjadzali, Islam dan Tata Negara Ajaran, Sejarah dan Pemik Iran, (Jakarta: UI Press, Edisi ke V, 1993), 7. 
dalam al-Qur'an dan Hadith, ini dikemukakan oleh Muhammad Musein Haikal.

Abu A'la al-Maududi merupakan figur Pemikir Islam yang meletakkan pondasi pemikiran tentang Islam sebagai "Way of Life", penulis merasa tertarik untuk mengungkapkan tentang pandangan politik Maududimengenai Negara Islam dalam bingkai pemikiran Islam. Abu A'la al-Maududi dilahirkan pada tanggal 3 Rajab $1321 \mathrm{H}$ bertepatan dengan 23 September 1903 di Aurangabad India Selatan, sekarang dikenal dengan Andra Pradfesh, ia wafat pada 23 September 1979 di New York. Ayahnya bernama Sayyid Ahmad Hasan, keturunan wali sufi Tarikat Chishti, termasuk penyebar Islam di benua India. ${ }^{5}$ Sayyid Ahmad hasan seorang hakim yang taat, ia menutup praktek pangacaranya karena selalu merasa tidak sesuai dengan isi hatinya. Disamping itu ia termasuk orang pertama yang masuk ke Sekolah Tinggi Anglo-Orienta Muslim yang dipimpin Sayyid Khan, ikut eksprimen dengan modernis Islam, setelah keluar dari Aligarh, ia menyelesaikan studi Hukum di Allahabad. Abu A'la al-Maududi, anak kecil dari tiga bersaudara diberikan pendidikan tradisional, ia dididik di rumah oleh ayahnya kemudian dilanjutkan ke Madrasah Fauqaniyah, yang menggabungkan pendidikan Tradisional dengan Pendidikan Barat, di sini ia belajar ilmu kimia, ilmu alam, dan matematika. Karena ia cerdas maka dapat menyelesaikan studi tepat pada waktunya dan mendapat ijazah Maulawi, nilai tertinggi, kemudian ia melanjutkan ke Perguruan Tinggi Dar al-Ulum di Hydrabad, tempat mencetak ulama India masa itu. Pada usia empat belas tahun telah menguasai Bahasa Arab dan Urdu dengan baik sehingga bisa menterjemahkan

${ }^{5}$ Sayyid Vali Reza Nashr, Para Perintis Zaman Baru Islam, (Bandung: Mizan, Cet I, 1995), 110. 
“al-Mar'at al-Jadidah” karya Qasim Amin ke bahasa Urdu.Karya ini dikenal hingga kini dengan isu emansipasi wanita dalam Islam.

Maududi pada usia 16 tahun ayahnya sakit keras dan meninggal dunia. Ia mengakhiri pendidikan formalnya karena kekurangan biaya, namun ia tetap belajar secara otodidak. Ia menguasai Bahasa Persia dan Inggris, rajin membaca sastra Arab, filsafat, mantik, tafsir dan hadith. Ketika berusia 20 tahun ia menunjukkan minat di bidang jurnalistik dan akhirnya tampil sebagai wartawan yang piawai, ia menulis lebih dari 200 buku dan artikel, juga risalah pendek mengenai-mengenai masalah-masalah agama, sosial dan politik. Jika dibandingkan dengan pemikir lainnya, maka Maududi sangat produtif menuangkan ide-idenya lewat tulisan atau seorang Fundamentalis, pada awalnya ia mempunyai semangat Nasionalis, ia sempat menulis beberapa esai yang memuji pemimpin partai kongres, Mahatma Gandhi dan Madan Muham Malaviya sekitar 1918-1919.

Terkait politik Islam menurut Maududi ada tiga pokok landasan tentang kenegaraan menurut Islam: ${ }^{6}$

1. Islam adalah suata agama yang paripurna, lengkap dengan petunjuk untuk mengatur semua segi kehidupan manusia, termasuk kehidupan politik. Dengar arti di dalam Islam terdapat sistem politik. Oleh karenanya dalam bernegara umat Islam tidak perlu atau bahkan dilarang meniru sistem barat. Cukup kembali ke sistem Islam dengan menunjuk pada politik semasa Khulafa alRasyidin sebagai model kenegaraan menurut Islam.

2. Kekuasaan tertinggi yang ada dalam istilah politik disebut kedaulatan, adalah pada Allah. Umat manusia

${ }^{6}$ Sjadzali, Islam dan Tata Negara, 165 
hanyalah sebagai pelaksana dari kedaulatan Allah tersebut sebagai khalifah-khalifah Allah di bumi, dengan demikian maka tidak dapat dibenarkan kedaulatan rakyat sebagai pelaksana kedaulatan Allah. Umat manusia atau negara harus patuh kepada hukum-hukum sebagaimana tercantum di dalam al-Qur'an dan al-Hadith. Sedangkan yang dimaksud khalifah-khalifah Allah yang berwenang melaksanakan kedaulatan Allah itu adalah orang laki-laki dan perempuan Muslim.

3. Sistem politik Islam adalah sistem universal, tidak mengenal batas dan ikatan-ikatan geografis, bahasa dan kebangsaan. $^{7}$

c. Secular Muslims

Pengertian Sekularisme secara etimologi berasal dari kata saeculum (bahasa latin), mempunyai arti dengan dua konotasi waktu dan lokasi: waktu menunjukkan kepada pengertian, "sekarang" atau "kini", dan waktu menunjukkan kepada pengertian "dunia" atau "duniawi". Sekularisme juga memiliki arti fashluddin anil hayah, yang itu memisahkan peran agama dari kehidupan yang berarti agama hanya mengurus hubungan antara individu dengan penciptanya saja. $^{8}$

Maka sekularisme secara bahasa dapat diartikan sebagai faham yang hanya melihat kehidupan saat ini saja dan di dunia ini. Tanpa ada perhatian sama sekali kepada hal-hal spiritual seperti adanya kehidupan setelah kematian yang notabene adalah inti dari ajaran agama. Sekularisme secara terminologi sering didefinisikan

${ }^{7}$ Saeed, Islamic Thought, 146 $18-19$.

${ }^{8}$ Syed Naquib al-Attas, Islam dan Sekulerisme, (Bandung: Pustaka, 1981), 
sebagai sebuah konsep yang memisahkan antara negara (politik) dan agama.Yaitu bahwa negara merupakan lembaga yang mengurus tatanan hidup yang bersifat duniawi dan tidak ada hubungannya dengan yang berbau akhirat, sedangkan agama adalah lembaga yang hanya mengatur hubungan manusia dengan hal-hal yang bersifat metafisis dan bersifat spirtual, seperti hubungan manusia dengan Tuhan.Maka menurut para sekuler, negara dan agama yang dianggap masing-masing mempunyai kutub yang berbeda tidak bisa disatukan masing- masing haruslah berada pada jalurnya sendiri-sendiri. Paham sekuler ini pertama mulai mendunia ketika Harvey Cox, menulis sebuah buku berjudul " The Seculer City”. Dimana menurut Cox, sekulerisasi adalah akibat logis dari dampak kepercayaan Bible terhadap sejarah. Selanjutnya, ada tiga komponen penting dalam Bible yang menjadi kerangka asas menuju sekularisasi, yaitu "disentchantmen of nature" yang dikaitkan dengan penciptaan, "desacralization of politics" dengan migrasi besar-besaran kaum Yahudi dari Mesir. Selanjutnya "deconsecration of values" dengan perjanjian sinai. ${ }^{9}$ Jadi menurut Cox, sekularisasi adalah pembebasan manusia dari asuhan agama dan metafisika, pengalihan perhatiannya dari dunia lain menuju dunia kini. Karena sudah menjadi satu keharusan, kata Cox, maka kaum kristen tidak seyogyanya menolak sekularisasi. Sebab sekularisasi merupakan konsekuensi otentik dari kepercayaan bible.Maka, tugas kaum kristani adalah menyokong dan memelihara sekularisasi.

Perlu diperhatikan adalah adanya perbedaan antara sekularisasi dan sekularisme. Menurut Syed Naquib al-Attas, sekularisasi adalah suatu proses yang berkelanjutan dan berakhir terbuka dimana nilai-nilai dan pandangan-pandangan dunia secara

${ }^{9}$ Adian Husaini, Wajah Beradaban Barat: Dari Hegemoni Kristen ke Dominasi Sekuler-Liberal, (Jakarta: GIP, 2005), 257. 
terus menerus diperbaharui sesuai perubahan evalusioner sejarah. ${ }^{10}$ Jadi, sekularisasi merupakan proses keterbukaan pandangan pada nilai-nilai yang berlansung tiada ujung yang selalu berevolusi sesuai dengan zaman dan keadaan manusia. Ada tiga komponen integral yang ada dalam sekularisasi, yaitu: pertama, Disentchantmen of nature, kedua, Desacralization of politics, ketiga, Deconsecration of values.Disentchantmen of nature sebuah istilah yang dipinjam dari ahli sosiologi jerman, Max Weber: yang memiliki maksud pembebasan alam dari nada-nada keagamaan, memisahkannya dari Tuhan dan membedakan manusia dari padanya, yang dengan demikian membolehkannya untuk berbuat bebas terhadap alam. Alam menurut paham ini sama sekali tidak mempunyai nilai-nilai sakral bahwa alam sebenarnya adalah ciptaan Tuhan yang selanjutnya manusia ditugaskan sebagai penjaga untuk melestarikannya.

Dari penindak-keramatan alam ini sebenarnya mendorong terlahirnya faham atheisme atau yang sedikit lebih halus dari atheisme, yaitu agonitisisme.Bagaimana tidak, ketika alam dilepaskan dari sifatnya yang supranatural, metafisis secara halus itu berarti menolak kepercayaan bahwa alam diciptakan oleh Tuhan yang akhirnya mendorong kepada keyakinan bahwa Tuhan tidak ada.Karena secara agnotisisme, ketika Tuhan sebagai esensiden eksistensi yang tidak mungkin dibuktikan keberadaannya baik secara akal maupun secara empiris, maka tidak ada bedanya meyakini apakah Tuhan itu ada atau tidak.Itulah istilah halus dari atheisme, agnotisisme.

Desacralization of politics, yaitu penghapusan legitimasi sakral kekuasaan politik, seperti dipraktekkan oleh Kristen Barat di masa lalu yang menganggap kekuasaan politik sebagai warisan Tuhan sehingga ada dogma yang menyatakan bahwa menghianati

\footnotetext{
${ }^{10} \mathrm{Al}$-Attas, Islam dan Sekulerisme, 23
} 
penguasa berarti menghianati Tuhan.Hal ini yang melahirkan sekularisme dengan disakralisasi politik sebagai sebagai salah satu komponennya. Sekularisme memerlukan komponen itu untuk menghapus legitimasi sakral politik sebagai prasyarat untuk terjadi perubahan politik yang selanjutnya akan mendorong terjadinya perubahan sosial kemudian diakhiri dengan perubahan sejarah. Karena sejarah menurut sekularisme adalah rekayasa dan perencanaan manusia tanpa adanya campur tangan Tuhan di dalamnya.Maka tentu yang namanya rekayasa perlu kepada skenario yang matang, dan disakralisasi politik ini adalah salah satu dari skenario pembentukan sejarah versi manusia.

Deconsecration of values, yaitu pemberian makna semantara dan relatif kepada semua karya-karya budaya setiap sistem nilai, termasuk agama serta pandangan-pandangan hidup yang bermakna mutlak dan final. Dengan demikian sikap manusia terhadap semua nilai-nilai menjadi relatif dan beranggapan bahwa manusia bebas untuk menciptakan perubahan-perubahan nilai dan menghilangkan nilai pandangan yang bersifat mutlak. Yang berarti semua nilai-nilai itu bersifat nisbi.

Perbedaan antara sekularisasi dan sekularisme terletak pada komponen yang ketiga, yaitu Deconsecration of values.Jika dalam sekularisasi, semua nilai-nilai bersifat nisbi, selalu berubah-berubah, dan tidak pernah mutlak. Maka, sekularisme tidak pernah mendekonsekrasikan nilai-nilai karena ia membentuk sebagai sistem nilai sendiri dengan maksud agar dipandangan sebagai mutlak dan final.

Jadi, sekularisme tidak seperti sekularisasi yang menisbikan semua nilai dan memberikan keterbukaan bagi perubahan.Dari alasan inilah mereka (Barat) menanggap sekularisme sebagai ancaman yang harus diwaspadai dan diawasi oleh negara agar tidak menjadi ideologi negara. 
Berbeda dengan the political Islamist, the secular muslims justru melihat Islam terbatas pada domain kepercayaan pribadi dan hubungan antara individu dengan Tuhannya. Mereka sangat menghargai tingkat kesalehan individu atau kesalehan pribadipribadi sehingga mereka menganggap tidak perlu untuk membentuk negara Islam atau untuk menerapkan hukum Islam. ${ }^{11}$

d. Theological Puritans

Berbicara teologi puritan, Abdullah Saeed setidaknya memotret ajaran Wahabi.Oleh sebab itu, sebelum membahas ajaran teologi puritan Wahabi, alangkah baiknya mengetahui sejarah singkat Wahabi.Aliran teologi Wahabi muncul penghujung abad-18 di semananjung Jazirah Arabiyah dan terkait erat dengan kondisi dunia Islam saat itu. Seperti terekam dalam sejarah, masa keemasan

${ }^{11}$ Untuk menggambarkan lebih detail tentang pemikiran kelompok ini, maka Abdullah Saeed mendapatkan dan menampilkan sebuah dokumen yang disebut "Manifesto Seorang Muslim Sekuler" yang diajukan oleh seorang Muslim Perancis sebagai berikut: a) kami menolak dengan tegas menyatakan dan tindakan misogini, homophobia, dan anti semit yang dijalankan atas nama Islam. Tiga ciri ini yang menandakan Islam Politik yang telah berkuasa terlalu lama di beberapa negara asal kami. Kami berperang menentang mereka di sana (negara asal) dan kami berperang melawan mereka di sini (perancis). b) kami dengan tegas berkomitmen untuk persamaan hak laki-laki dan perempuan. Kami menentang penekanan terhadap perempuan yang menjadi subjek hukum status pribadi seperti al-Jazair. c) kami percaya bahwa pengakuan atas keberadaan kaum homoseksual dan kebebasan bagi mereka untuk menjalankan kehidupannya sendiri adalah kemajuan yang tak dapat ditolak lagi. Selama tidak melanggar hukum, baik hetroseksual maupun homoseksual sama saja. Tentang pilihan seksual seseorang adalah hak individu bukan masalah yang harus diurus oleh negara. d) akhirnya kami menolak dengan tegas pernyataan anti semit atas nama Islam. Kami melihat adanya pemanfaatan konflik Palestina-Israel sebagai alat promosi anti semit oleh kelompok-kelompok fundamentalis. e) Meskipun kami menolak kebijakan Israel akhir-akhir ini namun kami menolak penggambaran yang yang primitif tentang Yahudi. Kami mengakui hak Israel untuk tetap eksis, namun pada saat yang bersamaan kami juga berkomitmen untuk mendukung rakyat Palestina untuk membentuk negara dan terbebas dari penduduk. ( Saeed, Islamic Thought, 146147). 
Islam mulai runtuh bersamaan dengan semakin lemahnya tiga kerajaan besar Islam terakhir, Usmani di Turki, Safawi di Persia, dan Mughal di India pada rentang tahun 1500-1800 M.

Efektifitas tiga kerajaan tersebut mulai menurun pada akhir abad-18 dan runtuh pada abad sesudahnya.Meskipun Usmani baru berakhir pada awal abad-20, kekuasaannya sepanjang abad-19tidak lagi mengakar.Berhadapan dengan kekuatan Eropa yang semakin meningkat.Usmani akhirnya runtuh dan digantikan oleh sistem pemerintahan modern.Sejak itu masyarakat Muslim di seluruh dunia masuk dalam situasi kemunduran. ${ }^{12}$

Dalam situasi kemunduran Islam itu, lahirlah gerakan Wahabi yang dipelopori Muhammad Ibn Abd Wahhab di jazirah Arab, yang penekannya lebih pada pemurnian ajaran Islam dengan corak gerakan yang terbilang keras.Muhammad Ibn Wahhab ignin mengembalikan Islam pada sumbernya yang asli yaitu al-Qur'an dan hadith Nabi yang shahih, serta sekaligus melakukan gerakan pemberantasan terhadap praktik.Praktik syirik, bid'ah, dan khurafat yang meluas kala itu secara lansung dan keras, seperti pemusnahan bangunan-bangunan kuburan yang dikeramatkan.

Wahabi juga secara positif menekankan syariah, menentang sufisme, faham-faham mistis, filsafat Islam dan hampir keseluruhan tradisi intelektual Islam. Maka berkembanglah sebuah "rasionalisme" yang dipadukan dengan "puritanisme", berdasarkan suatu sikap yuridis dan teologis yang banyak dipengaruhi oleh tulisan-tulisan Ibn Taimiyah beserta pengikut-pengikutnya, dan 1998), 10.

${ }^{12}$ Tarmizi Taher et al, Radikalisme Agama, (Jakarta: PPM-UIN Jakarta, 
mempersempit kehidupan intelektual Islam yang luas menjadi porsi kecil dari keluasan tradisionalnya yang semula. ${ }^{13}$

Menurut Wahabi, tauhid yang diajarkan Nabi Muhammad Saw, telah diselubungi khurafat dan faham kesufian. Masjid-masjid banyak ditinggalkan karena orang lebih cenderung menghias diri dengan azimat, penangkal penyakit, dan tasbih.Mereka belajar pada seorang fakir atau darwis serta memuja mereka sebagai orang-orang suci dan sebagai perantara mencapai Tuhan.Dalam keyakinan mereka Tuhan terlalu jauh untuk dicapai oleh manusia melalui pemujaan secara lansung. Tidak hanya kepada guru yang masih hidup, kepada yang sudah mati pun mereka memohon perantaraan. Sebagai umat sudah meninggalkan akhlak yang diajarkan al-Qur'an, bahkan banyak tidak yang tidak menghiraukan lagi.Kota-kota suci Mekah dan Madinah telah menjadi tempat yang penuh dengan penyimpangan akidah, bid'ah, dan khurafat.

Tumbuh suburnya prilaku keagamaan semacam ini sesuai dengan tingkat kesejahteraan kebanyakan umat.Kekacauan politik telah menyebabkan timbul di segala tempat.Sistem kabilah merupakan tradisi lama bagi mayoritas penduduk Najd dan kebanyakan penduduk semenanjung Arabia.Kabilah-kabilah yang kuat dapat menguasai jalur perdagangan, sedangkan penduduk pada umumnya berada dalam kekurangan.Pertanian dan peternakan yang merupakan mata pencarian utama kebanyakan penduduk tidak dapat menjamin kehidupan ekonomi mereka. Hal ini disebabkan keagamaan yang rawan akibat dari kekacauan, peperangan, dan perampokan yang dilakukan oleh kabilah-kabilah lain. Akibtanya, penduduk Najd dan semenanjung Arabia kebanyakan hidup dalam kemiskinan.Di tengah kancah kehidupan yang demikian lahirlah

\footnotetext{
${ }^{13}$ Seyyed Hossein Nasr, Islam dan Nestapa Manusia Modern, (Bandung: Pustaka-Perpustakaan Salman ITB Bandung, 1983), 146.
} 
Wahabi sebagai gerakan keagamaan yang berusaha memurnikan agama Islam dan segala pemahaman dan praktek yang sudah menyimpang dari tunutunan yang sebenarnya. ${ }^{14}$

Ajaran Wahabi berpusat pada tauhid yang pada dasarnya terdiri dari tiga bagian: pertama, tauhid al-Rububiyah, kedua, tauhid al-asma' wa al-sifat (hanya membenarkan nama-nama dan sifat-sifat yang disebut dalam dalam al-Qur'an, tanpa disertai upaya untuk menafsirkan dan tidak diperbolehkannya untuk menerapkan namanama itu kepada siapapun selain Tuhan, bahkan seperti karim (dermawan), misalnya, tauhid al-ibadah (seluruh ibadah hanya ditujukan kepada Allah).

Bentuk tauhid yang terakhir ini adalah yang terpenting dalam pandangan Muhammad Ibn Abd Wahhab, baik dalam skema doktrinnya yang kaku maupun dalam penilaiannya yang cenderung memandang rendah kondisi kaum Muslim selama berabad-abad. Dalam menolak seluruh konsensus ulama sebelumnya, ia menganggap komponen pertama tauhid sebagai sekedar pengakuan verbal, yang tidak memiliki nilai pada dirinya sendiri dan tentu tidak memadai untuk mencapai kualitas sebagai Muslim. Karena, menurutnya bahkan kalangan politis Arab pra-Islam telah mempercayainya.Ia juga tidak memperlihatkan perhatian yang besar untuk mengalaborasi bentuk tauhid kedua, selain hanya mengulangi rumusan-rumusan Ibn Taimiyah yang mengecam antropomorfisme. Bentuk yang tauhid yang ketigalah, menurut Muhammad Ibn A'la Abd Wahhab yang menjadi batas tegas antara Islam dan kufur, antara tauhid dan syirik.

Termasuk dalam argumennya ialah bahwa prinsip tauhid alibadah dan diwahyukan kepada Nabi bahkan sebelum kewajiban-

\footnotetext{
${ }^{14}$ Ibid, 157
} 
kewajiban ibadah seperti shalat, zakat, puasa dan haji yang memungkinkan prinsip itu diterjemahkan ke dalam praktik, dan karena itu memiliki nilai yang lebih unggul dibandingkan kewajiban-kewajiban ibadah tersebut. seperti halnya tauhid alrububiyah tidak cukup untuk menjadikan diri seseorang sebagai Muslim, orang juga tidak dapat mencapai kualitas sebagai Muslim dengan melaksanakan kewajiban-kewajiban agamanya jika ia melanggar prinsip tauhid al-ibadah sebagaimana didefinisikan oleh sekte Wahabi.

e. Militant Extremists

Munculnya isu-isu politis mengenai radikalisme Islam merupakan tantangan baru bagi umat Islam untum menjawabnya.Isu radikalisme Islam ini sebenarnya sudah lama mencuat di permukaan wacana internasional.Radikalisme Islam sebagai fenomena historissosiologis merupakan masalah yang banyak dibicarakan dalam wacana politik dan peradaban global akibat kekuatan media yang memiliki potensi besar dalam menciptakan persepsi masyarakat dunia. Banyak label-label yang diberikan oleh kalangan Eropa Barat dan Amerika Serikat untuk menyebut gerakan Islam radikal, dari sebutan kelompok garis keras, ekstrimis, militan, Islam kanan, fundamentalisme sampai terrorisme.

Bahkan di negara-negara Barat pasca hancurnya ideologi komunisme (pasca perang dingin) memandang Islam sebagai sebuah gerakan dari peradaban yang menakutkan. ${ }^{15}$ Tidak ada gejolak politik yang lebih ditakuti melebihi bangkitnya gerakan Islam yang diberinya label sebagai radikalisme Islam. Tuduhan-tuduhan dan 1995), 270.

${ }^{15}$ Nurcholis Madjid, Pintu-pintu Menuju Tuhan, (Jakarta: Paramadina, 
propaganda Barat atas Islam sebagai agama yang menopang gerakan radikalisme telah menjadi retorika internasional.

Dalam perspektif Barat, gerakan Islam sudah menjadi fenomena yang perlu dicurigai. Terlebih pasca hancurnya gedung WTC New York yang dituduhkan dilakukan oleh kelompok Islam garis keras (al-Qaeda dan Taliban) semakin menjadikan term radikalisme Islam menjadi wacana yang lebih menglobal yang berimplikasi pada sikap kecurigaan masyarakat dunia, terutama bangsa Barat dan Amerika Serikat terhadap gerakan Islam. Hal yang demikian terjadi karena orang-orang Eropa Barat dan Amerika Serikat berhasil dalam melibatkan dan mewarnai media sehingga mampu membentuk opini publik.

Praktik-praktik kekerasan yang dilakukan sekelompok Islam dengan membawa simbol-simbol agama telah dimanfaatkan oleh orang-orang Barat dengan memanfaatkan media massa sebagai alat utama dalam memegang tampuk wacana peradaban, sehingga Islam terus menerus dipojokkan oleh publik. Barangkali masyarakat Barat telah tertipu oleh muslihat peradabannya sendiri dalam mengeksploitasi media yang diciptakannya. John L. Esposito menjelaskan bahwa terjadinya kebangkitan Islam didorong oleh tiga hal: pertama, adanya krisis identitas yang menimbulkan ketidakberdayaan, kekecewaan dan kehilangan harga diri. Kedua, kekecewaan terhadap barat akibat dari kegagalan pemerintah yang tidak bisa mengatasi bobroknya sistem ekonomi, sosial maupun politik dalam masyarakat.Ketiga, tampilnya kembali rasa bangga dan harga diri akibat suksesnya militer (Arab-Israel) dan Ekonomi (embargo minyak) pada tahun 1971.

Abdullah Saeed menyajikan tiga model gerakan militant extrimist kaum Muslim pada abad ke-20 dan awal abad ke- 
21.Pertama, perjuangan pembebasan nasional atau transnasional dengan area lokal tiap-tiap negara.Kedua, perjuangan internasional atau transnasional, seperti perang Afganistan oleh laskar Mujahidin sebagai respon terhadap pendudukan Soviet.Ketiga, gerakan anti barat yang dilancarkan oleh ekstrimis militan semisal Osama bin Laden. ${ }^{16}$

Gelombang noe-revivalisme Islam menjadi sebuah fenomena sejak dekade 1970-an di Timur Tengah. Namun secara historis, realitas fenomena ini telah ada sejak dekade terbentuknya Ikhwanul Muslimin pada akhir 1920-an. Kebangkitan Islam sejak dekade tersebut ditandai maraknya perjuangan pengaplikasian ajaran Islam secara menyeluruh.Dalam kehidupan budaya, hubungan sosial, persoalan-persoalan ekonomi, dan kehidupan politik.Terciptanya Islam kaffah (utuh) dalam berbagai sektor kehidupan menjadi tujuan utama gelombang neo-revivalisme ini.

Fenomena kebangkitan Islam memiliki beberapa bentuk.Hal umum yang terjadi adalah kesadaran masyarakat untuk berprilaku religiussesuai norma-norma Islam.Berbeda dengan revivalisme Islam abad ke-18yang hanya menekankan sisi legalitas penerapan syariat, neo-revivalisme berorientasi mewujudkan syariat Islam sebagai sebuah bentuk ideologi politik. ${ }^{17}$ Bentuk kebangkitan Islam tidak lagi terbatas pada tingginya kesadaran beribadah ritual belaka, tetapi juga menempatkan Islam sebagai sebuah ideologi dalam rangka mewujudkan hakimiyyat Allah (kedaulatan Tuhan) melalui persatuan umat Islam secara global.Pada fenomena ini terdapat serangkaian aktivisme keagamaan yang meliputi kelompokkelompok pergerakan dan masyarakat Islam militan.Kelompok-

\footnotetext{
${ }^{16}$ Saeed, Islamic thought, 149.

${ }^{17}$ Pipes, Daniel, In the name of God, (New Jersey: Transaction Publishers, 2002). 124
} 
kelompok ini memiliki kesadaran tinggi dalam memperjuangkan ideologi Islam sehingga sering bertentangan dengan pemerintah, negara, serta lembaga-lembaganya.

\section{Progressif ijtihadis yang ditawarkan oleh Abdullah Saeed}

Islam jihadis mengidentifikasi Islam dengan pilar tunggal yaitu jihad, kemudian melanjutkannya dengan menawarkan interpretasi ulang terhadapnya.Kunci terhadap perdebatan ini adalah rangkulan Islam jihadis terhadap tindak kekerasan.Sebagai hal yang sentral dari perubahan sosial dan politik.Bagaimana seseorang bisa memahami perkembangan Islam jihadis sebagai tendensi teologis? Dapatkah pemahaman partikularnya terhadap teks al-Qur'an dicerahkan oleh konteks perubahan historisnya?tentu saja iya.

Islam jihadis kontemporer yang merangkul kekerasan politik harus dipahami sebagai sebuah proyek modernis, tetapi bukan sebagai sisa masa premodern yang tertinggal di zaman modern ini. Kekerasan telah berada pada hati modernitas politik: setidaknya sejak revolusi Perancis (1789), masyarakat modern telah memikirkan tentang kekerasan sebagai sentral untuk maju. Diktum Marx bahwa revolusi adalah dukun beranak dari sejarah adalah bagian dari perspektif modernis ini. Tidak ada abad yang sama mengasikkan dengan dengan kemajuan abad ke-20, dan tidak ada yang lebih keras. Tetapi harus diingat bahwa mereka yang hidup selama masa abad itu sangat mungkin untuk berfikir dari yang paling keras "revolusi" perang-perang dunia, sebagai kekerasan "yang baik" bukan "kekerasan yang jahat".

Perjuangan jihad Afganistan merupakan rumah panas dimana pelaku utama (protagonist) yang memunculkan perang melawan teror saat ini -neocons (neo-konservatif) dan jihad secara ideologis dan politis. Dalam reformulasi mereka tentang Islam sebagaimana 
yang berhenti pada saat rukun/pilar jihad sebagian besarnya militer, dan dari jihad militer tidak lagi tentang pertahanan diri masyarakat tetapi pernyataan yang tegas darii dari seseorang individu, Islam jihadis harus dipahami sebagai bentuk Islam yang bangun kembali sebagai lawan dari Kristen dan Yahudi bangun kembali di masa kontemporer ini. Pola pikir emosional Islam jihadis yang cenderung menawarkan kekerasan dalam setiap sikap politik dan keagamaan selain dipengaruhi oleh faktor eksternal juga dipengaruhi oleh cara pandang dan pemikiran terhadap Islam. Oleh karena itu, perlu mengubah cara pandang tekstual ke kontekstual dengan jalan jihad progresif

Abdullah Saeed mengindentifikasi tiga model ijtihad yang menurutnya sangat berpengaruh pada masa masing-masing sepanjang sejarah hukum Islam:

Pertama, adalah text based ijtihad, yakni metode ijtihad yang lazim digunakan oleh fuqaha' klasik dan masih memiliki banyak pengaruh di kalangan pemikir tradisionalis. Pada model ini teks berkuasa penuh, baik itu nass Qur'ani, hadith maupun pendapat ulama sebelumnya baik yang berupa ijma' atau qiyas.

Kedua, eclectic ijtihad, yakni upaya memilih nas atau pendapat ulama sebelumnya yang paling mendukung pendapat dan posisi yang diyakininya.Yang ada hanyalah jastifikasi bukan kebenaran.

Ketiga, context-based ijtihad, sebuah fenomena baru yang mencoba memahami maslah-masalah hukum dalam konteks kesejarahan dan konteks kekiniannya (modern). Biasanya, pendapat akhir akan mengacu pada kemaslahatan umum sebagai maqasid al-Syari'ah. ${ }^{18}$

\footnotetext{
${ }^{18}$ Saeed, Islamic Thought, 55
} 
Ijtihad model ketiga inilah yang dilakukan oleh para progressive ijtihadists. Kalau metodelogi klasik biasanya memecahkan permasalahan hukum dengan mendasarkannya pada teks al-Qur'an, kemudian memahami apa yang dikatakan teks tentang permasalahan tersebut, dan paling jauhnya kemudian menghubungkan teks itu dengan konteks sosio-historisnya, maka progressive ijtihadists mencoba lebih jauh lagi menghubungkan dengan konteks kekinian seperti Esack, Irshad Manji, Ebrahim Moosa dan tentu Khaled Abou el-fadl.

Berkaitan dengan bagaimana metodologi progessive ijtihadists menafsirkan ulang teks-teks al-Qur'an, Abdullah Saeed memaparkan tujuh pendekatan utama yang tidak jauh berbeda dengan Abou al-fadl, yaitu:

a. Atensi pada konteks dan dinamika sosio-historis,

b. Menyadari bahwa ada beberapa topik yang tidak dicakup oleh al-Qur'an karena waktunya belum tiba pada waktu diturunkannya al-Qur'an,

c. Menyadari bahwa setiap pembacaan atas teks kitab suci harus dipandu oleh prinsip kasih sayang, justice and fairness,

d. Mengetahui bahwa al-Qur'an mengenal herarki nilai-nilai dan prinsip,

e. Mengetahui bahwa dibolehkan berpindah dari satu contoh konkret pada generalisasi atau sebaliknya,

f. Kehati-hatian harus dilakukan ketika menggunakan teks lain dari tradisi klasik, khususnya yang berkaitan dengan otentisitasnya, 
g. Fokus utama pada kebutuhan muslim kontemporer. ${ }^{19}$

Pendekatan terhadap teks seperti inilah yang menurut Abdullah Saeed akan mampu memberikan jawaban atas permaslahatan kontemporer. Dengan ijtihad progresif inilah diharapkan mampu melahirkan "fiqih deasporik" yang dapat menjadi solusi terhadap problem-problem keagamaan muslim diaspora. Fiqih deasporik bisa juga digunakan sebagai langkah awal adaptasi dan integrasi budaya yang berperspektif tamu dan tuan rumah.

\section{KESIMPULAN}

Abdullah Saeed dapat dikategorikan sebagai Mujtahid Kontemporer, karena disamping menguasai turast dia juga memiliki ketajaman analisis sebagai paduan antara "ulum al-Dien" dengan ilmu-ilmu sosial modern lainnya. Juga dikarenakan sikapnya yang cenderung ilmiah dengan mengutamakan penelitian, basis datanya sebagaimana ditekankan dalam filsafat ilmunya Charles S. Pierrce dan juga konsep epistimologi Burhan-nya Abid al-Jabiri.Bahkan bersepakat dengan Arkoun yang mengkritik sikap Muslim yang mentaqdiskan al-afkar al-Diniyyah dengan menggagas sikap independen dari madzhab. Dan untuk mendapatkan gagasan Islam Progressif dengan progresif ijtihadis sebagai metodenya, maka meminjam perspektif Kim Knott, Abdullah Saeed telah memposisikan diri sebagai participant as Observer dalam konteks studi pemetaan trend pemikiran muslim kontemporer dan sekaligus sebagai Complete Muslim Participant dalam hal membangun sikap,

${ }^{19} \mathrm{IDSS}$, "Progressive Islam and The State in Contemporary Muslim Societies."Laporan seminar diadakan di Marina Mandarin Singapure tanggal 7-8 Maret 2006, 5. 
210 |Rausyan Fikr, Vol. 12 No.2 Desember 2016: 181 - 210

konsep dan gagasannya tentang Islam progressifnya melalui berbagai karya.

\section{DAFTAR PUSTAKA}

Arkun, Muhammad, al-Fikr al-Islamy: Naqdu wa Ijtihad, (Bairut: alMuassisah al-Wathaniyah li al-Kitab, 1989)

al-Attas, Syed Naquib, Islam dan Sekulerisme, (Bandung: Pustaka, 1981)

Husaini, Adian, Wajah Beradaban Barat: Dari Hegemoni Kristen ke Dominasi Sekuler-Liberal, (Jakarta: GIP, 2005)

IDSS, "Progressive Islam and The State in Contemporary Muslim Societies."Laporan seminar diadakan di Marina Mandarin Singapure tanggal 7-8 Maret 2006

Madjid, Nurcholis, Pintu-pintu Menuju Tuhan, (Jakarta: Paramadina, 1995)

Nashr, Sayyid Vali Reza, Para Perintis Zaman Baru Islam, (Bandung: Mizan, Cet I, 1995)

Nasr, Seyyed Hossein, Islam dan Nestapa Manusia Modern,(Bandung: Pustaka-Perpustakaan Salman ITB Bandung, 1983)

Pipes, Daniel, In the name of God, (New Jersey: Transaction Publishers, 2002). 124

Saeed, Abdullah, Islamic Thought and Introduction, (New York: Routledge, 2006)

Sjadzali, Munawir, Islam dan Tata Negara Ajaran, Sejarah dan Pemik Iran, (Jakarta: UI Press, Edisi ke V, 1993) 
Afifullah, Konsep Ijtihad Progresif Abdullah Saed | 211

Taher, Tarmizi et al, Radikalisme Agama, (Jakarta: PPM-UIN Jakarta, 1998)

www.abdullahsaeed.org 